\title{
As Influências da Psicanálise na Educação Brasileira no Início do Século XX
}

\author{
Jorge Luís Ferreira Abrão ${ }^{1}$ \\ Universidade Estadual Paulista
}

\begin{abstract}
RESUMO - O presente artigo tem por objetivo discutir, a partir de um vértice histórico, a relação entre educação e psicanálise no Brasil. Partindo de um estudo qualitativo, fundamentado na análise bibliográfica relativa à produção psicanalítica dedicada à educação produzida no país nas primeiras décadas do século XX, são discutidas as contribuições da psicanálise na transformação das práticas educacionais. Os resultados indicam que a psicanálise esteve presente na educação de duas formas: inicialmente, pela divulgação de informações teóricas relativas aos conceitos psicanalíticos e às características do desenvolvimento emocional da criança, por intermédio de livros e cursos destinados a educadores, e, posteriormente, através da criação de uma prática de assistência ao escolar com problemas de aprendizagem ou comportamento, desenvolvida em clínicas de orientação infantil, que consistia na avaliação da criança e na orientação de pais e professores. Conclui-se que a psicanálise, enquanto fundamento teórico e prático, forneceu elementos que contribuíram para a sustentação dos pressupostos filosóficos da "Escola Nova", que surgiu, a partir da década de 1920, como alternativa ao ensino tradicional.
\end{abstract}

Palavras-chave: psicanálise; educação; criança.

\section{The Influences of Psychoanalysis on Brazilian Education in the Beginning of the $20^{\text {th }}$ Century}

\begin{abstract}
The present article aims at discussing, from a historical point of view, the relationship between education and psychoanalysis in Brazil. Starting from a qualitative study, based on the bibliographical analysis relative to the psychoanalytic production dedicated to education produced in this country in the first decades of the 20th century, the contributions of psychoanalysis in the transformation of the educational practices are discussed. The results show that psychoanalysis was present in education in two ways: firstly by turning public the theoretical information related to psychoanalytic concepts and to the characteristics of child emotional development, through books and courses designed for educators and, afterwards, through the creation of an assistance practice to scholars with learning or behavior problems, developed in child orientation clinics, which consisted on child evaluation and parents and teachers orientation. We conclude that psychoanalysis, while a theoretical and practical fundament, supplied elements which contributed to the support of the philosophic presumptions of a new educational model that came up as from 1920 as an alternative to traditional teaching.
\end{abstract}

Key words: psychoanalysis; education; child.

O interesse concernente à relação entre educação e psicanálise é bastante antigo, sendo esta temática discutida desde a obra de Freud, em diversas passagens esparsas ao longo de seus trabalhos. Particularmente a partir da década de 1910, este assunto encontrou lugar de destaque na obra de alguns seguidores do pai da psicanálise, entre os quais devemos destacar Ferenczi (1908), Oskar Pfister (1921) e Melanie Klein (1921), para citarmos apenas os mais relevantes.

O volume significativo de trabalhos sobre o tema, sua importância tanto para a pedagogia quanto para a psicanálise e a convergência por vezes ambígua e controversa entre estas duas disciplinas têm motivado o surgimento de estudos dedicados a revisar ou compendiar as contribuições existentes sobre o assunto. Seguindo esta linha de teorização, encontramos os livros de Catherine Millot (1987) e Maria Cristina Machado Kupfer (1989), que procuram discutir a forma como o tema da educação é abordado na obra de Freud.

$\mathrm{Na}$ atualidade avolumam-se os trabalhos dedicados ao

1 Endereço: Rua Smith de Vasconcelos, 722/83, Assis, SP, Brasil 19814010.E-mail:abrao@assis.unesp.br (FAPESP). debate relativo às aproximações entre educação e psicanálise e, particularmente no Brasil, as pesquisas e as propostas de intervenção dedicadas ao tema têm sido bastante recorrentes. Particularmente nos últimos 10 anos, alguns trabalhos de expressão vieram a público, seja pelo caráter inovador das idéias neles veiculadas ou por introduzirem modelos de intervenção bastante originais no meio educacional. Entre estes estudos merecem destaque os livros Educação para o Futuro: Psicanálise e Educação, de Maria Cristina Kupfer, publicado em 2000; Educação e Psicanálise: história, atualidade e perspectiva, de 2003, organizado por Maria Lúcia de Oliveira e O Impacto da Psicanálise na Educação, editado em 2005 sob a coordenação de Leny Magalhães Mrech.

Apesar de todas estas iniciativas, poucos são os trabalhos dedicados a esquadrinhar, a partir de um vértice histórico, as influências da psicanálise na educação brasileira durante o século XX. As únicas publicações que indiretamente fazem este percurso são os livros A Psicanálise no Brasil, de Elizabeth Mokrejs, publicado em 1993, e A História da Psicanálise de Crianças no Brasil, escrito por Jorge Luís Ferreira Abrão e editado em 2001, que nasceram com o objetivo de estudar a história da psicanálise no Brasil, e ao longo dos estudos apontam muitas conexões da disciplina freudiana com a educação brasileira. 
Deste modo, somos concitados, no presente artigo, a compreender de forma mais detalhada as influências que a psicanálise exerceu sobre a educação no Brasil na primeira metade do século XX.

\section{Dos antecedentes históricos à delimitação da pesquisa}

O início do século XX marca uma série de transformações políticas, econômicas, sociais e culturais que alavancaram o desenvolvimento do país de forma significativa. $\mathrm{O}$ surgimento da psicanálise no Brasil figura na galeria dos acontecimentos de vulto que impuseram à década de $1920 \mathrm{a}$ marca da modernidade, reflexo de uma sociedade em franca transformação, que se abria para o novo, o desconhecido. Segundo Reinaldo Lobo (1994, p.50),

O final da primeira Guerra trouxe, portanto, um quadro histórico absolutamente diferente em vários níveis de atividade social e humana: a industrialização se acelerou, ainda que não em graus e em qualidade tecnológica só conhecidos após a Segunda Guerra Mundial; a legitimidade do sistema político, dominado pelos Partidos Republicanos (PRs) dos latifundiários cafeeiros e criadores, foi questionada; uma profunda alteração cultural e ideológica ocorreu entre as elites intelectuais. Um paradoxo do período foi a combinação de racionalismo crescente e voraz importação de novos modelos e novas idéias, vindas sobretudo da Europa. Os mais esclarecidos queriam saber de tudo o que se passava lá fora, "não para copiar", mas para "entender a realidade nacional". O advento da psicanálise foi um dos efeitos secundários desta mutação nacional: a modernização burguesa propiciou o aparecimento de projetos iluministas, como a criação da USP, no início dos anos 30, e mesmo a chegada "das coisas freudianas", como disse Mário de Andrade.

As transformações que destacamos acima viabilizaram a implantação das idéias psicanalíticas no Brasil e se constituíram também no substrato que conduziu a significativas modificações no modelo educacional vigente no país até então, fazendo com que a educação tradicional fosse perdendo espaço para uma nova filosofia educacional fundada no pensamento liberal, qual seja, a "Escola Nova".

Forjada no ideário liberal, a "Escola Nova", ou "Escola Progressista", como também ficou conhecida, surge no cenário educacional do país como uma opção ou mesmo como uma oposição ao ensino tradicional em vigor até então. Assim, esta nova política educacional partia do princípio de que a escola deveria atuar como um instrumento para a edificação da sociedade através da valorização das qualidades pessoais de cada indivíduo.

Seguindo esta linha de raciocínio podemos evidenciar a ênfase colocada nas peculiaridades da criança enquanto um ser em desenvolvimento, diferenciada do adulto e com uma lógica de pensamento própria. Neste sentido, torna-se vital compreender as características da criança para melhor gerir sua educação. Temos com isto um espaço fecundo para a introdução da psicologia no meio educacional, enquanto uma ciência habilitada a fornecer "(...) os meios necessários para que a escola renovada investigue melhor as características infantis e seja um lugar capaz de realizar plenamente os atributos de cada indivíduo." (Cunha, 1995, p. 41). É por esta mesma senda que a psicanálise encontrou espaço para se difundir dentro da educação, auxiliando tanto na compreensão do desenvolvimento emocional da criança, quanto na resolução das dificuldades escolares que impedem a expressão de suas potencialidades individuais.
Partindo do contexto enunciado acima, que marcou a introdução da psicanálise no Brasil e apontou as condições que viabilizaram a presença da psicanálise no meio educacional do país, conduzimos uma pesquisa qualitativa, de caráter histórico, que teve por objetivo analisar de forma detalhada as influências da psicanálise sobre a educação brasileira entre as décadas de 1920 a 1950.

Para a consecução deste objetivo, foi realizado um exaustivo levantamento bibliográfico, de forma a identificar todos os textos dedicados ao tema da psicanálise que veiculavam informações relativas às contribuições desta disciplina à educação publicados em livros, jornais e revistas no período em questão. Para efeitos de delimitação da pesquisa, foram adotados alguns critérios para a inclusão destes trabalhos, que descrevemos abaixo. Com relação aos autores, incluímos profissionais de diversas áreas que em algum momento escreveram sobre o tema, de tal forma que foram investigadas as contribuições de pedagogos, pediatras, psiquiatras, assistentes sociais, entre outros. No que tange às características dos trabalhos, analisamos tanto os textos teóricos que tinham por finalidade apresentar conceitos psicanalíticos a pais e professores, quanto trabalhos práticos cujo objetivo era demonstrar as possibilidades de aplicação do conhecimento psicanalítico à prática pedagógica ou à educação infantil.

Partindo destes critérios, foram identificados os seguintes autores com seus respectivos trabalhos: Deodato de Moraes, autor do livro A Psychanalyse na Educação (1927); Júlio Pires Porto-Carrero, com os artigos: "O Caracter do Escolar Segundo a Psychanalyse" (1927); "Instrucção e educação sexuais" (1928a), "Leitura para crianças: ensaio sob o ponto de vista psychanalytico" (1928b), "A arte de perverter: applicação psychanalytica à formação moral da criança" (1929a), "Educação sexual" (1929b) e "O que esperamos dos nossos filhos" (1930). Arthur Ramos, com os livros: Educação e Psychanalyse (1934a) e A Criança Problema (1939), além dos seguintes artigos: "A technica da psychanalyse infantil" (1933), "Os furtos escolares" (1934b), "A mentira infantil" (1937), "A dinâmica afetiva do filho mimado" (1938a) e "O problema psycho-sociológico do filho único" (1938b). Encontramos ainda Hosannah de Oliveira, com os artigos "O Complexo de Édipo em Pediatria" (1932) e "A hygiene mental do lactente" (1933); Gastão Pereira da Silva, com os livros: Educação Sexual da Criança (1934) e Como se Deve Evitar o Drama Sexual de Nossos Filhos (1939) e Pedro de Alcântara, com o artigo "Objeções da Psychanalyse ao Uso da Chupeta: Análise e Crítica" (1936). Na década de 1940, encontramos os trabalhos de Durval Marcondes: "A higiene mental escolar por meio da clínica de orientação infantil" (1941a), "Contribuição para o problema do estudo dos repetentes da escola primária: condições físicas, psíquicas e sociais" (1941b) e "Clínica de orientação infantil: sua finalidades e linhas gerais de sua organização" (1946a); os seguintes artigos de Virgínia Bicudo: "A visitadora social psiquiátrica e seu papel na higiene mental da criança" (1941), "Funções da visitadora psiquiátrica na clínica de orientação infantil e noções de higiene mental da criança" (1946a) e "Papel do lar na higiene mental da criança" (1946b) e as publicações de Lygia Alcântara do Amaral. "A apatia e o retraimento dos escolares como problema de higiene mental" (1941) e "Lar substituto e seu papel na higiene mental da criança" (1946).

$\mathrm{Na}$ seqüência, estes trabalhos foram classificados e, posteriormente, analisados. A classificação a que foram submetidos levou em conta: o período cronológico em que foram publicados, a natureza teórica ou prática do trabalho, o público alvo a que se destinavam os artigos e os conceitos 
psicanalíticos empregados na elaboração do texto. A análise realizada teve por objetivo avaliar o tipo de informação psicanalítica veiculada e identificar quais os principais modelos e concepções de aproximação entre educação e psicanálise.

Com base na classificação e na análise realizadas, identificamos a existência de dois períodos históricos nos quais a influência da teoria psicanalítica esteve presente de forma diferenciada no meio educacional brasileiro nas primeiras décadas do século XX. São eles: a divulgação da teoria psicanalítica junto aos educadores, que se estende do início da década de 1920 até meados da década de 1930, e a aplicação da psicanálise à higiene mental escolar, etapa compreendida entre a segunda metade da década de 1930 até aproximadamente 1950 .

\section{Divulgando a Psicanálise entre os educadores}

O marco inaugural que define a inserção da psicanálise no universo educacional brasileiro é encontrado no livro $A$ Psychanalyse na Educação, de autoria do Professor Deodato de Moraes $(1927)^{2}$. Esta obra pode ser considerada como a primeira publicação brasileira de cunho psicanalítico inteiramente dedicada à criança. Como é apontado no prefácio escrito pelo psiquiatra carioca Porto-Carrero (1927, p.112), "No Brasil, o prof. DEODATO DE MORAES escreve o primeiro livro de pedanalyse ${ }^{3}$ fruto de indefesso esforço que acompanhei de perto". Embora este livro fosse inteiramente dedicado ao educador, segundo as próprias palavras do autor, não encontramos em suas páginas nenhuma passagem que faça alusão às possíveis formas de aplicação da teoria psicanalítica junto à educação; ao contrário, este trabalho destina-se a uma apresentação teórica de conceitos psicanalíticos objetivando familiarizar o leitor com o jargão específico da área. Esta intenção fica evidente no teor didático da seguinte citação extraída do livro de Deodato de Moraes (1927, p. 18):

\footnotetext{
Assim como se confunde, em geral, o "consciente" com o "psychico" e nós nos apressamos em alargar a noção de "psychico" e de mostrar a existência de um psychico que não é consciente, a mesma identidade se apresenta ao se querer limitar o "sexual" à "procriação" ao "genital" e somos obrigados a demonstrar a existência de um "sexual" que não é "genital", que nada mesmo tem que ver com a procriação.
}

Outro fato significativo ocorrido no ano seguinte, portanto em 1928, no Rio de Janeiro, foi a realização, na Associação Brasileira de Educação, do Curso de Psicanálise Aplicada à Educação, ministrado pelo Prof. Deodato de Moraes e pelo Dr. Porto-Carrero, cuja aula inaugural ocorreu aos 20 de abril. O programa do referido curso pode ser encontrado na primeira edição do livro de Porto-Carrero, Ensaios de Psychanalyse, publicado em 1929, no qual podemos aferir a ocorrência de 21 aulas ministradas entre os meses de abril a julho. O tema das conferências constitui-se em uma ampla exposição da teoria freudiana, com assuntos

2 Deodato de Moraes foi Professor de Pedagogia e Psicologia Experimental da Escola Normal de São Paulo, Inspetor Escolar do Distrito Federal e membro do conselho diretor da Associação Brasileira de Educação.

3 Pedanalise é uma expressão introduzida pelo psicanalista suíço Oskar Pfister para designar a psicanálise de crianças, que foi empregada de forma ambígua pelos autores brasileiros, referindo-se em alguns momentos a psicanálise aplicada à educação e em outros ao tratamento psicanalítico de crianças. que vão desde a sexualidade infantil até a teoria dos sonhos, passando pela teoria dos símbolos e das neuroses.

Os temas apresentados neste curso não se dedicam a uma aplicação sistemática dos conhecimentos psicanalíticos à educação da criança, dando indícios de que o objetivo do referido curso é a divulgação dos conhecimentos produzidos por Freud, sem deixar muito claro como estas informações poderiam transformar-se em uma prática educacional efetiva. Esta característica torna-se bastante evidente na hesitação com que Deodato de Moraes (1927, p. 137) aborda o tema da sexualidade. Segundo ele,

\footnotetext{
Sem dúvida o educador não deverá perder a opportunidade de fazer explicações individuais, mas dirigir-se a classe seria de um effeito desastroso. Mesmo na iniciação individualizada é preciso lembrar que nem todos os mestres terão o dedo necessário para tocar em assumpto tão delicado. Seria talvez mais conveniente entregar o problema ao médico amigo da família. Assim o temos feito com o nosso filho de quatorze anos e com o mais satisfatório dos resultados.
}

Mais do que uma falha ou omissão deliberada dos ministrantes deste curso, a dificuldade de migrar da retórica para a prática sugere a inexistência de uma definição do que viria a ser uma prática educacional inspirada em princípios psicanalíticos, o que começará a surgir alguns anos mais tarde, através da iniciativa destes e de outros autores, na medida em que os conceitos introduzidos foram sendo melhor compreendidos e assimilados.

Após a ocorrência destes acontecimentos iniciais, iremos acompanhar, em um primeiro momento, o surgimento de vários trabalhos de natureza eminentemente teórica, dedicados ao tema da educação e da psicanálise e realizados por alguns precursores deste movimento científico no país. Destacaram-se como tal um séquiito de autores, quais sejam: o pedagogo Deodato de Moraes e os médicos Júlio Pires Porto-Carrero, Arthur Ramos, Hosannah de Oliveira, Gastão Pereira da Silva, e Pedro de Alcântara.

Analisados em conjunto, os autores acima arrolados definem uma importante etapa da história da psicanálise no Brasil, sobretudo no que tange a sua relação com a educação. Foram estes os primeiros teóricos que tomaram a iniciativa de difundir no meio científico e cultural brasileiro as primeiras formulações teóricas sobre a psicanálise, particularmente aquelas dedicadas às crianças, que começavam a surgir no continente europeu. Trata-se de um período marcado pela iniciativa e pela determinação de alguns homens devotados à causa psicanalítica, que não mediam esforços para compreender a teoria freudiana e expandir suas fronteiras.

Entre os autores que mais se destacaram dentro desta temática, encontramos o nome de Júlio Pires Porto-Carrero. Em seus trabalhos dedicados a este assunto, identificamos como marca distintiva uma preocupação em divulgar a teoria psicanalítica entre os professores tendo em vista que este autor salienta, de forma reiterativa, a necessidade de os professores compreenderem com maior exatidão os efeitos que as práticas pedagógicas exercem sobre os alunos. Afirma ele:

Vereis como a psychanalyse vos abrirá os olhos, para comprehenderdes as excellencias e os defeitos de vossa pedagogia. Vereis o quanto é mau educar recalcando e o quanto é optima a sublimação, quando não é possível a destruição, a condemnação dos complexos. (Porto-Carrero, 1928a, p. 23) 
A dimensão deste aforismo pode ser melhor compreendida quando analisamos o artigo intitulado "O Caracter do Escolar Segundo a Psychanalyse", apresentado no I Congresso Nacional de Educação, ocorrido em Curitiba no ano de 1927. Nele encontramos um guia prático que permite ao professor compreender diferentes manifestações afetivas de seus alunos, discriminando e analisando, a partir da perspectiva psicanalítica, alguns tipos de caráter mais freqüente entre os escolares: os tímidos, os travessos e os rebeldes.

Mais que um exercício diletante, de valor meramente especulativo, a classificação proposta por Porto-Carrero tem uma função audaciosa: a de introduzir o mestre no pensamento freudiano, aproximando-o da teoria da sexualidade infantil. Apesar desta finalidade, suas contribuições não ultrapassam o campo teórico, uma vez que, após apresentar estas conclusões aos professores, não aponta nenhuma indicação de como estas diferentes manifestações afetivas dos alunos podem ser abordadas durante o trabalho pedagógico, de forma a favorecer a aprendizagem dos alunos e a proporcionar-lhes condições mais favoráveis para um desenvolvimento saudável, por intermédio de uma educação menos coercitiva, e que leve em conta as características da criança.

Por seu turno, Arthur Ramos (1903-1949), na primeira fase de seu trabalho anterior ao ingresso no Serviço de Ortofrenia e Higiene Mental, apresenta em sua obra característica semelhante àquela encontrada em Porto-Carrero, divulgando conceitos psicanalíticos e teorizando sobre suas possíveis influências na educação. Sua principal obra neste período, Educação e Psychanalyse (1934a), teve por finalidade, de acordo com o autor, vulgarizar a teoria psicanalítica junto aos educadores, auxiliando-os a entender o comportamento de seus alunos. Para tal busca, concilia os conhecimentos psicanalíticos com o ideário escolanovista o que, segundo o autor, permitiria sustentar uma gestão educacional calcada em uma visão progressista do ensino. Esta concepção é explicitada com nitidez no primeiro capítulo denominado "A escola nova e a psychanalyse", no qual, após apresentar os fundamentos conceituais da "Escola Nova", Arthur Ramos dedica-se a discutir as contribuições da psicanálise neste contexto. Comenta ele:

A sua intromissão na pedagogia é perfeitamente válida, tanto nos fins como nos meios da educação. Se esta visa uma ordenação das relações humanas, a psychanalyse contribui a desvendar as imperfeições originárias, destacando e demonstrando, de outro lado, as tendencias á ordenação que existem também em estado inconsciente no homem. Fornece ainda um methodo de estudo, que favorece a resolução de certas situações pedagógicas “difficeis", e insolúveis sem o seu auxílio. (1934a, p.15).

Fato digno de nota é a posição assumida pelo autor ao afirmar que, para empregar a psicanálise na prática pedagógica, o professor necessita, além de conhecimento teórico, algum tipo de experiência psicanalítica. Sustenta ele: "Para uma orientação pedagógica de base psychanalytica é indispensável a correta formação mental do educador" (Ramos, $1934 a$, p. 161). No entanto, este autor não esclarece como dar exequiibilidade à proposta de promover o que chama de formação mental do analista. Ao que nos parece, Arthur Ramos tinha uma compreensão bastante apurada de que apenas conhecimento teórico de psicanálise não seria suficiente para influenciar a prática pedagógica do professor, sendo necessário complementar sua formação com uma análise pessoal ou algo semelhante, condições muito difíceis de serem implantadas na época e que, por isto, ficaram no plano meramente retórico.

Ao cotejarmos os trabalhos destes autores, podemos evidenciar que eles não se apropriavam da psicanálise enquanto um instrumento terapêutico que lhes conferisse uma identidade profissional. Ao invés disso, tomavam este conhecimento como um sistema teórico passivo de ser aplicado a diversas áreas do saber, particularmente à educação. É neste sentido que iremos perceber a eleição de alguns temas em detrimento de outros, o que confere uma característica comum à obra psicanalítica dos teóricos nacionais que se destacaram neste período.

Assim, as questões de natureza clínica parecem ter despertado pouco interesse, ficando mesmo relegadas a segundo plano, salvo em alguns casos isolados, como na atuação do pediatra baiano Hosannah de Oliveira, que empregou a teoria psicanalítica em sua clínica pediátrica, tanto para fundamentar suas hipóteses diagnósticas quanto para orientar pais no tocante à educação de seus filhos. Provavelmente, esta característica decorre da dificuldade ou mesmo da impossibilidade de se conduzir um trabalho de natureza clínica em psicanálise de crianças, haja vista que nesta ocasião não havia no país pessoas com formação para desempenhar tal tarefa, além do que a psicanálise de crianças sempre foi entendida como um procedimento bem mais complexo do que a de adultos.

Os temas de maior atenção dos autores há pouco mencionados foram aqueles voltados para a educação da criança, seja na família ou no âmbito escolar. Na tentativa de explicar tal fato, podemos aventar a hipótese de que a seleção deste assunto ocorreu por ser o tema da educação de crianças inspirada na psicanálise, de maior aceitação e de mais fácil aplicação, servindo, desta forma, ao propósito de divulgar a teoria psicanalítica.

Ao empregarem a teoria psicanalítica na educação de crianças, estes autores tinham como meta uma intervenção de natureza profilática, proporcionando à criança condições favoráveis de desenvolvimento, de forma a evitar que o distúrbio de ordem emocional viesse a se instalar e comprometer o ajustamento de sua personalidade. Neste sentido, os professores deveriam ser informados sobre as hipóteses psicanalíticas relativas ao desenvolvimento infantil para melhor gerir a educação de seus alunos, compreender suas dificuldades escolares e, em última análise, formar indivíduos emocionalmente saudáveis.

A forma de utilização da psicanálise no cuidado da criança que se difundiu no meio educacional brasileiro no início do século XX circunscreveu sua intervenção em um período anterior ao surgimento de uma possível patologia e encontra-se em perfeita consonância com o pensamento vigente na psiquiatria brasileira neste período. Fundada em um ideal eugênico, a psiquiatria brasileira da década de 1920 direcionava sua atenção para a área da saúde mental, o que foi concretizado em 1923, com a criação, no Rio de Janeiro, da Liga Brasileira de Higiene Mental. De acordo com esta tendência,

Sobretudo a partir de 1926, os psiquiatras começaram a enunciar suas novas concepções de prevenção. Eles pretendiam tornar a prevenção psiquiátrica similar à prevenção em medicina orgânica. A ação terapêutica deveria exercer-se no período pré-patogênico, antes do aparecimento dos sinais clínicos. Esta concepção leva-os a dedicar um maior interesse na prevenção da saúde mental. Daquele momento em diante, o alvo de cuidado dos psiquiatras passou a ser o indivíduo normal e não o doente. O que interessava era a prevenção $e$ não a cura. (Freire Costa, 1976, p. 33) 
Uma vez apresentados estes argumentos, podemos concluir que os autores aqui estudados, ao entrarem em contato com a teoria psicanalítica, não renunciaram ao ideal eugênico que os inspirava, em benefício de uma aplicação terapêutica da psicanálise, o que fica patente particularmente em Porto-Carrero. Ao contrário, estes teóricos incorporaram a psicanálise aos valores vigentes na psiquiatria da época, utilizando seu arcabouço teórico para fundamentar o trabalho profilático que começava a ser realizado. Isto fica mais evidente quando destacamos os trabalhos concernentes à psicanálise de crianças, nos quais a proposta de uma intervenção preventiva por intermédio da educação figurava como eixo central. Fato este que justificava a divulgação da psicanálise no meio educacional.

Em uma análise retrospectiva, podemos considerar que as principais contribuições dos precursores da psicanálise de crianças no Brasil residem em difundir no país as formulações psicanalíticas, sobretudo aquelas voltadas à infância, conquistando credibilidade social e científica, o que serviu de alicerce para o surgimento, nos anos subseqüentes, de propostas de atendimento à criança, fundadas em princípios psicanalíticos.

\section{Aplicação da Psicanálise à Higiene Mental $^{4}$ Escolar}

Chegamos assim a um segundo período, que se caracterizou pela aplicação dos conhecimentos relativos à psicanálise de crianças à higiene mental escolar, por intermédio de Clínicas de Orientação Infantil ${ }^{5}$ que prestavam assistência ao escolar deficitário.

Dentro desta filosofia, foi criada no Rio de Janeiro, em 1933, a Seção de Ortofrenia e Higiene Mental, que estava vinculada ao Instituto de Pesquisas Educacionais do Distrito Federal. Por indicação de Anísio Teixeira (1900-1971) foi convidado para chefiar este serviço o médico alagoano Arthur Ramos, precursor da psicanálise no Brasil.

Em São Paulo, proposta semelhante foi efetivada por intermédio da fundação, em 1938, de uma Seção de Higiene Mental Escolar junto ao Departamento de Educação da então Secretaria de Estado da Educação e Saúde Pública. A direção da referida seção ficou a cargo de Durval Marcondes (1899-1981), destacada figura do movimento psicanalítico em São Paulo.

Encontramos no trabalho desenvolvido nestas instituições, tanto no Rio de Janeiro, por intermédio da Seção de Ortofrenia e Higiene Mental, como em São Paulo, através da Seção de Higiene Mental Escolar, o nascedouro de uma prática clínica com crianças, inspirada em princípios psicanalíticos fortemente vinculados à educação.

Partindo dos relatos encontrados em algumas publicações da época, particularmente nos livros A Criança Problema, de autoria de Arthur Ramos (1939), e Noções Gerais de Higiene Mental da Criança, organizado por Durval Marcondes (1946b), é possível reunir elementos suficientes

4 O termo "higiene mental" refere-se ao que entendemos hoje como saúde mental. A mudança de nomenclatura foi sugerida pela Organização Mundial da Saúde, em 1949.

5 As clínicas de orientação infantil criadas pelos serviços de higiene mental escolar no Brasil foram inspiradas nas child garden clinic norteamericanas.

6 Entre os teóricos nacionais que empunharam a bandeira da "Escola Nova", figura com grande destaque o nome de Anísio Teixeira que, após estudar com o filósofo John Dewey (1858-1952) nos Estados Unidos, trouxe para o Brasil suas idéias sobre esta nova filosofia educacional, implantando-as no ensino municipal do Rio de Janeiro na década de 1930, o que ficou conhecido como "Reforma Anísio Teixeira". para apresentar, mesmo que de forma sucinta, algumas informações relativas às características, à natureza e à filosofia do trabalho desenvolvido nas clínicas de orientação infantil dirigidas por estes autores.

Em linhas gerais, o atendimento ao escolar deficitário oferecido pelas clínicas de orientação infantil era composto por duas etapas principais: avaliação e orientação. Na primeira delas, a criança era submetida a um procedimento que se assemelha ao que denominamos na atualidade de psicodiagnóstico, mediante a realização de avaliação por uma equipe multiprofissional que envolvia psicólogos ${ }^{7}$, assistentes sociais, psiquiatras e pediatras. Uma vez identificada a origem das dificuldades manifestadas pela criança, dava-se início à segunda etapa do trabalho, através da orientação de pais e professores com o objetivo de promover modificações ambientais necessárias à remissão das dificuldades encontradas. Devemos salientar que, ao longo de todo o processo de avaliação da criança e orientação dos pais e educadores, como ficou demonstrado por Abrão (2001), o trabalho era fortemente sustentado nos fundamentos teóricos da psicanálise.

Cabe ressaltar que a abrangência e a importância da higiene mental escolar, seja na sua versão paulista seja na carioca, assume grande magnitude, uma vez que este trabalho agrega contribuições que permitem refletir sobre o surgimento, no Brasil, de uma prática de atendimento inspirada na psicanálise de crianças, sobre a origem da psicopedagogia na escola primária brasileira e ainda sobre a relação entre a Psicanálise e a Instituição, tema tão em voga atualmente. Apesar de relevantes, não nos coube, no âmbito deste trabalho, abrir um parêntese para colocar em tela estas questões; procuramos apenas ressaltar aqueles aspectos que apresentam alguma ligação com o tema relativo às conexões entre psicanálise e educação no Brasil.

Resguardadas as diferenças entre as clínicas de orientação infantil de São Paulo e as do Rio de Janeiro, os atendimentos nelas desenvolvidos guardam alguma semelhança entre si que favoreceram o surgimento de uma prática em psicanálise de crianças. Provavelmente, a semelhança mais relevante para o presente estudo é a distinção estabelecida entre criança-problema e criança deficiente, que na pedagogia tradicional eram classificadas sob um único rótulo: o de criança anormal. Esta concepção fica evidente a partir das conclusões apresentadas por Arthur Ramos em 1939, após cinco anos de atuação como diretor do Serviço de Ortofrenia e Higiene Mental. Para ele,

A nossa experiência no exame dos escolares "dificeis" mostrou que havia necessidade de inverter os dados clássicos da criança chamada "anormal”. Esta denominação - imprópria em todos os sentidos - englobava o grosso das crianças que por várias razões não podiam desempenhar os seus deveres de escolaridade, em paralelo com os outros companheiros, os "normais".(...) A grande maioria porém podemos dizer os $90 \%$ das crianças tidas como "anormais", verificamos na realidade serem crianças difíceis, "problemas", vítimas de uma série de circunstâncias adversas (Ramos, 1939, p. 13).

Estes serviços de higiene mental entendiam que a crian-

7 Os profissionais que exerciam as atividades que foram regulamentadas, em 1962, como atribuições do psicólogo eram denominados de psicologistas quando exerciam atividades de aplicação de teste, ou visitadoras psiquiátricas, ao desempenharem atribuições como visitas domiciliares ou escolares. 
ça-problema, ao contrário da deficiente, tinha suas dificuldades forjadas na relação entre suas necessidades individuais e o meio social em que estavam inseridas. É no bojo desta concepção que encontramos espaço para o surgimento da psicanálise de crianças associada à higiene mental, prática esta que, em anos subseqüentes, serviu de esteio para o surgimento da análise de crianças propriamente dita.

A etapa aqui descrita marca o início de um período de transição na história da psicanálise de crianças no Brasil. Deixando para trás uma fase, na qual a psicanálise de crianças encontrava espaço social e científico apenas na retórica, com a difusão de informações sobre educação infantil, este período inaugura uma nova forma de compreender a psicanálise e sua aplicação à criança, através da inclusão de preceitos psicanalíticos na assistência ao escolar deficitário.

A natureza do atendimento oferecido às crianças-problema pelas clínicas de orientação infantil, apesar de migrar do campo da retórica para a prática, ainda não atribuía à psicanálise de crianças o estatuto de um sistema terapêutico aplicado ao tratamento dos distúrbios emocionais da infância, à semelhança da análise de adultos, uma vez que sua intervenção tinha uma finalidade de caráter profilático e apenas secundariamente assumia funções terapêuticas.

Devemos ressaltar, no entanto, a conotação com que o termo profilático é empregado neste contexto histórico. Não se trata unicamente de atribuir aos pais e professores a função precípua de agentes profiláticos de futuras manifestações de doença mental, por intermédio de uma educação infantil guiada por princípios psicanalíticos, embora esta função pudesse advir secundariamente. $O$ foco principal para o qual foram direcionados os esforços dos profissionais que atuavam nas clínicas de orientação infantil era o de promover a prevenção da doença mental, através da compreensão e da assistência às manifestações sintomáticas da criança em idade escolar. A esse respeito, assim escreveu Durval Marcondes (1946a, p. 44):

A moléstia mental do adulto é, o mais das vezes, o produto final de um processo de desadaptação que, sob formas diversas, já se vinha manifestando desde a época da infância. A clínica em apreço vai surpreender e tratar esse processo em seu início, quando são maiores as probabilidades de sua produção.

Desta forma, constatamos que a conotação profilática atribuída à higiene mental escolar não trazia em sua proposta de trabalho o signo da eugenia, que foi uma marca constante dos primeiros textos de divulgação da psicanálise de crianças no Brasil, nos quais o redirecionamento da educação das crianças, com base na psicanálise, era apontado como condição essencial para a saúde mental do indivíduo. A partir desta iniciativa concretizada nas clínicas de orientação infantil, a prevenção em saúde mental começou a ser praticada dentro da seara da clínica, tendo na psicanálise seu principal pilar de sustentação, e garantindo às crianças que potencialmente poderiam tornar-se neuróticas na vida adulta a assistência necessária a suas manifestações afetivas durante a infância.

\section{Conclusão}

Tendo por base estes resultados, podemos concluir que, durante a primeira metade do século XX, existiu uma estreita relação entre educação e psicanálise no Brasil. Esta forte presença da psicanálise no discurso pedagógico brasileiro deveu-se a uma série de fatores, alguns inerentes à própria psicanálise e outros relativos à educação brasileira.

No que concerne à psicanálise, devemos considerar que as iniciativas de aproximação com a educação foi um tema amplamente debatido na Europa desde a década de 1910, ao se acreditar que uma educação guiada por princípios psicanalíticos favoreceria o desenvolvimento de uma personalidade saudável e evitaria o surgimento de sintomas neuróticos na vida adulta. Além disso, a psicanálise, ou mais especificamente o ramo da ciência psicanalítica dedicado à psicanálise de crianças, encontrou na educação sua primeira via de inserção no país, haja vista que as condições para o surgimento de um trabalho de cunho estritamente psicoterápico ainda não existia

Por outro lado, a educação brasileira da década de 1920, período em que as influências psicanalíticas começaram a chegar ao país, encontrava-se em um processo de transformação, incorporando uma filosofia educacional que considerava a criança em toda a sua singularidade. Tal condição foi bastante propícia para a penetração das idéias psicanalíticas, uma vez que esta teoria dispunha de um arcabouço teórico bastante sedimentado e relativo ao desenvolvimento do psiquismo infantil, às relações interpessoais e aos problemas emocionais da criança, que davam sustentação à filosofia da "Escola Nova".

Esta área de intersecção entre educação e psicanálise na primeira metade do século XX percorreu dois momentos distintos, porém complementares: a divulgação da teoria psicanalítica no meio educacional, através da iniciativa de alguns precursores da psicanálise no Brasil, que preconizavam em seus trabalhos teóricos uma intervenção de natureza profilática, e aplicação da psicanálise à higiene mental escolar, mediante a atenção às manifestações sintomáticas do escolar, através de diagnóstico e orientações de país e professores, o que foi viabilizado por clínicas de orientação mantidas por serviços de higiene mental escolar no Rio de Janeiro e São Paulo.

Com base no tipo de discurso e prática empregados pelos autores aqui estudados, podemos concluir que a noção de criança, enquanto categoria de desenvolvimento, e de infantil, como representação das experiências infantis no psiquismo seja do adulto ou da criança, confundem-se para estes autores. Neste sentido, evidencia-se que a idéia de infantil, enquanto uma categoria atemporal que influencia a conduta humana consciente, cuja investigação permitiria entender as diferentes manifestações da vida mental no presente, é negligenciada ou ao menos ofuscada, em favor de uma visão mais pragmática que privilegia e valoriza os aspectos relativos ao desenvolvimento infantil, o que justifica as intervenções voltadas para a profilaxia e o diagnóstico. Neste sentido, fica evidente que a psicanálise foi tomada, no meio educacional brasileiro, como um instrumento prático destinado a promover o ajustamento do aluno na escola e não como um recurso para a compreensão da subjetividade da criança.

Além dos efeitos exercidos pela psicanálise junto à educação brasileira no momento histórico em questão, cabe destacar ainda as influências deste período para as discussões atuais sobre o tema. Primeiramente cabe enfatizar que os encontros entre educação e psicanálise no Brasil não se restringiram às iniciativas aqui descritas; neste sentido, as discussões sobre o tema que tiveram lugar no início do século XX reverberam até a atualidade mediante a incorporação de novas problemáticas e diferentes modelos de intervenção, como pode ser observado nos trabalhos de Maria Cristina Kupfer (2000) e Maria Lúcia de Oliveira (2003).

Uma importante oscilação entre os trabalhos da primeira metade do século XX e aqueles encontrados na atualidade diz respeito à forma de intervenção no meio educacional, que passou a considerar a importância do aspecto relacional entre aluno e professor, a contemplar a noção de infantil 
enquanto uma categoria inconsciente, atemporal e presente, tanto na criança como no adulto e a sustentar uma prática que busque a formação integral do professor que detenha conhecimento teórico de psicanálise e experiências pessoais que permitam aproximá-lo de suas vivências inconscientes, de suas experiências infantis recalcadas. Em conjunto, estes elementos favorecem uma melhor compreensão do aluno por parte do professor, que passa a atuar como um mediador no processo ensino-aprendizagem.

\section{Referências}

Abrão, J. L. F. (2001). A história da psicanálise de crianças no Brasil. São Paulo: Escuta.

Alcântara, P. (1936). Objecções da psychanalyse ao uso da chupeta: análise e crítica. Revista da Associação Paulista de Medicina, 9(5), 385-387.

Amaral, L. A. (1941). A apatia e o retraimento dos escolares como problema de higiene mental. Revista de Neurologia e Psiquiatria de São Paulo, 7(6), 299-302.

Amaral, L. A. (1946). Lar substituto e seu papel na higiene mental da criança. Em D. Marcondes (Org.), Noções gerais de higiene mental da criança (pp.119-131). São Paulo: Livraria Martins Editora.

Bicudo, V. L. (1941). A visitadora social psiquiátrica e seu papel na higiene mental da criança. Revista de Neurologia e Psiquiatria de São Paulo, 7(6), 293-298.

Bicudo, V. L. (1946a). Funções da visitadora psiquiátrica na clínica de orientação infantil e noções de higiene mental da criança. Em D. Marcondes (Org.), Noções gerais de higiene mental da criança (pp. 79-89). São Paulo: Livraria Martins Editora.

Bicudo, V. L. (1946b). Papel do lar na higiene mental da criança. Em D. Marcondes (Org.), Noções gerais de higiene mental da criança (pp. 101-110). São Paulo: Livraria Martins Editora.

Cunha, M. V. (1995). A educação dos educadores: da "Escola Nova" à escola de hoje. Campinas: Mercado das Letras.

Ferenczi, S. (1991). Psicanálise e Pedagogia. Em Psicanálise I - Obras Completas (pp. 35-40). (A. Cabral, Trad.). São Paulo: Martins Fontes (Trabalho original publicado em 1908).

Freire Costa, J. (1976). História da psiquiatria no Brasil. Rio de Janeiro: Campus.

Klein, M. (1996). O desenvolvimento de uma criança. Em Amor, culpa e reparação (pp. 22-75). (A. Cardoso, Trad.). Rio de Janeiro: Imago (Trabalho original publicado em 1921).

Kupfer, M. C. (2000). Educação para o futuro: psicanálise e educação. São Paulo: Escuta.

Kupfer, M. C. (1989). Freud e a Educação: o mestre do Impossível. São Paulo: Scipione.

Lobo, R. (1994). As mudanças históricas e a chegada da psicanálise no Brasil. Em L. Nosek (Org.), Álbum de Família: imagens, fontes e idéias da psicanálise em São Paulo (pp. 49-55). São Paulo: Casa do Psicólogo.

Marcondes, D. B. (1941a). A higiene mental escolar por meio da clínica de orientação infantil. Revista de Neurologia e Psiquiatria de São Paulo, 7(6), 252-258.

Marcondes, D. B. (1941b). Contribuição para o problema do estudo dos repetentes da escola primária: condições físicas, psíquicas e sociais. Revista de Neurologia e Psiquiatria de São Paulo, 7(6), 263-271.

Marcondes, D. B. (1946a). Clínica de orientação infantil: suas finalidades e linhas gerais de sua organização. Em D. B. Marcondes (Org.), Noções gerais de higiene mental da criança (pp. 43-48). São Paulo: Livraria Martins Editora.
Marcondes, D. B. (Org.) (1946b). Noções gerais de higiene mental da criança. São Paulo: Martins Editora.

Millot, C. (1987). Freud Antipedagogo. Rio de Janeiro: Zahar

Mokrejs, E. (1993). A psicanálise no Brasil. Petrópolis: Vozes.

Moraes, D. (1927). A psychanalyse na educação. Rio de Janeiro: Mendonça, Machado \& Cia. Editores.

Mrech, L. M. (Org.) (2005). O impacto da psicanálise na educação. São Paulo: Avercamp.

Oliveira, H. (1932). O complexo de Édipo em pediatria. Bahia Medica, 3(1), 306-309.

Oliveira, H. (1933). A hygiene mental do lactente. Archivos Brasileiros de Hygiene Mental, 6(2), 221-233.

Oliveira, M. L. (Org.) (2003). Educação e Psicanálise: história, atualidade e perspectiva. São Paulo: Casa do Psicólogo.

Pfister, O. (1959). El psicanálisis y la educacion. Buenos Aires: Losada. (Trabalho original publicado em 1921)

Porto-Carrero, J. P. (1927). O caracter do escolar segundo a psychanalyse. Em J. P. Porto-Carrero (Org.), Ensaios de psychanalyse (pp. 41-59). Rio de Janeiro: Flores \& Mano Editores.

Porto-Carrero, J. P. (1928a). Instrucção e educação sexuais. Em J. P. Porto-Carrero (Org.), Ensaios de psychanalyse (pp. 71-79). Rio de Janeiro: Flores \& Mano Editores.

Porto-Carrero, J. P. (1928b). Leitura para crianças: ensaio sob o ponto de vista psychanalytico. Em J. P. Porto-Carrero (Org.), Ensaios de psychanalyse (pp. 165-176). Rio de Janeiro: Flores \& Mano Editores.

Porto-Carrero, J. P. (1929a). A arte de perverter: applicação psychanalytica à formação moral da criança (pp. 133-142). Em J. P. Porto-Carrero (Org.), Ensaios de psychanalyse. Rio de Janeiro: Flores \& Mano Editores.

Porto-Carrero, J. P. (1929b). Educação sexual. Archivos Brasileiros de Hygiene Mental, 2(1), 120-133.

Porto-Carrero, J. P. (1930). O que esperamos dos nossos filhos. Revista da Associação Brasileira de Educação, 1(3),71-77.

Ramos, A. (1933). A technica da psychanalyse infantil. Archivos Brasileiros de Hygiene Mental, 6(2), 195-205.

Ramos, A. (1934a). Educação e psychanalyse. São Paulo: Companhia Editora Nacional.

Ramos, A. (1934b). Os furtos escolares. Archivos Brasileiros de Hygiene Mental, 7(2), 229-235.

Ramos, A. (1937). A mentira infantil. Revista Médica da Bahia, 5(10), 195-210.

Ramos, A. (1938a). A dinâmica afetiva do filho mimado. Neurobiologia, 1(1), 265-287.

Ramos, A. (1938b). O problema psycho-sociologico do filho único. Revista Médica da Bahia, 6(9), 185-200.

Ramos, A. (1947). A criança problema (4a. ed.). Rio de Janeiro: Livraria Editora da Casa do Estudante do Brasil. (Trabalho original publicado em 1939)

Silva, G. P. (1934). Educação sexual da criança. Rio de Janeiro: Editora Mariza.

Silva, G. P. (1939). Como se deve evitar o drama sexual dos nossos filhos. Rio de Janeiro: Oscar Mano \& Cia. Editores.

Recebido em 01.11.2005

Primeira decisão editorial em 06.02.2006

Versão final em 06.04.2006

Aceito em 28.04.2006 